\title{
A Comparative Study of the Effect of Mint Leaf Extract and Silver Nanoparticle on the Male Rats Treated with Ethidium Bromide
}

\author{
Nawres Adnan Abdulameer \\ Technical Institute of Al-Diwaniyah, Al-Furat Al-Awsat Technical University (ATU) Iraq \\ Corresponding author email: dw.noras@atu.edu.iq
}

\section{ABSTRACT}

The present study was conducted for the purpose of verifying the effect of silver nanomaterial and comparing it with mint leaf extract on male rats treated with ethidium bromide. Where 50 male rats were selected and divided into 5 groups as follows:Control group 10 males rats gavage distilled water for 30 days, Ethidium bromide group 10 males rats gavage distilled water for 30 days, Ethidium bromide and mint leaf extract(40g/L) group 10 males rats for 30 days, Ethidium bromide and silver nanoparticle group 10 males rats for 30 days, Ethidium bromide and (silver nanoparticle, mint leaf extract) group 10 males rats for 30 days.And after sacrificed males rats we collected tissues samples from testis to extraction of RNA to evaluated of LH,FSH and testosterone by qPCR technique and tissues to make tissues section to knowledge changes in testis. The results of the current study, which was conducted on male rats, showed that there is a positive effect of mint leaves extract as well as a negative effect of silver nanoparticles on the level of gene expression for all study groups in each of the LH hormone, FSH hormone and testosterone compared to the control group as shown in the Fig 1,2 and 3. And showed in figure 4, several normal seminiferous tubules with normal spermatogonia cell, normal Sertoli cells, normal germ cell layer with normal maturation stages; interstitial spaces show an area of interstitial congestion; the lumen devoid of spermatozoa with interstitial congestion; normal seminiferous tubules with normal spermatogonia cell, normal Sertoli cells, and normal germ cell layer; maturation arrest of tubules and mild interstitial congestion; seminiferous tubules with atrophy exhibiting thick double cell layers indicative of cessation of spermatogenesis.

\section{KEY WORDS: MINT LEAVE, SILVER NANOPARTICLE, LH, FSH AND TESTOSTERONE.}

\section{INTRODUCTION}

The Lamiaceae family is one of the families of flowering plants (Naghibi et al 2005) and genus Mentha, an important member of this family, has 6 species in the flora. These species have great importance in folk medicine and are available in traditional medicinal plant stores and local markets (Amin 2005). Spearmint is one of these species, with a good flavor and fragrance, used worldwide in pharmaceutical preparations, confectionery

Biosc Biotech Res Comm P-ISSN: 0974-6455 E-ISSN: 2321-4007

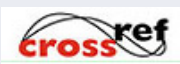

Identifiers and Pagination

Year: 2021 Vol: 14 No (7) Special Issue

Pages: 196-200

This is an open access article under Creative

Commons License Attribn 4.0 Intl (CC-BY).

DOI: $h t t p: / / d x . d o i . o r g / 10.21786 / b b r c / 14.7 .46$ and food industries, and also in hygiene and cosmetic products (Kumar et al 2005 and Spirling and Daniels 2001). Some studies have been shown that spearmint oil has anti-fungal, anti-microbial, anti-inflammatory, antitumor and antioxidant activity (Guimaraes et al 2011 and Pearson et al 2012).

Furthermore, various beneficial medicinal effects of spearmint have been found, such as preventing chemotherapy-induced nausea and vomiting (CINV), treatment of respiratory and digestive system disorders, hypertension, anxiety and even for relieving menstrual pain (Cakilcioglu et al 2011 and Tayarani-Najaran et al 2013). Spearmint is mainly recommended for its antispasmodic effects, which are related to its carvone content, the most important constituent of spearmint (29-74\%). Spearmint also contains 4-24\% limonene, $0.21-2.1 \%$ volatile oil and 3-18\% cireole (Akdogan et al 2007).Nanoparticles (NPs) are particles that are designed
Article Information

Received: $12^{\text {th }}$ May 2021

ccepted after revision: $14^{\text {th }}$ July 2021 
and produced with a dimension or size that is $\leq 100$ nanometers (Fathi, et al 2019).

Fertility, reproduction, and fetal development are essential to the sustenance of aspecies, highlighting the importance of the growing public awareness of the toxicity of NPs on thereproductive system. Recent studies have indicated an increased incidence of male reproductivedefects, including low sperm production in adulthood, hypospadias, cryptorchidism, and testicularcancer (Pothuraju, et al 2013). This increased incidence of male reproductive defects may be partly attributable toenvironmental contaminant exposure. Thus, the wide use and environmental persistence of NPshave raised concerns about the negative impact on human health, especially on the reproductivesystems and fetal health (Talebi, et al 2013). Nanoparticles have diaerent effects on sperm cell functions either upon direct exposure underin vitro conditions or if administered in vivo (Shittu et al 2018).

The ability of NP to cross the hemato-testicular barrierhas been demonstrated raising concerns about their distribution and biocompatibility at the system ic level. Several studies have reported the e_ects of Ag-NPs on epididymis, testis, and sperm function parameters in di_erent animal species. However, the e_ects of NPs on oxidative stress and spermatogenesis need to be investigated on a case-by-case basis due to the administered concentration, and duration of treatment (Adenubi et al 2010).

\section{MATERIAL AND METHODS}

\section{Study design}

Fifty male rats weights (180 \pm 10 gm), aged 90 days were selected and divided into 5 groups as follows:

1. C:Control group 10 males rats gavage distilled water for 30 days.

2. T1:Ethidium bromide (10 mg/kg b.w.) group 10 males rats gavage distilled water for 30 days.

3. T2:Ethidium bromide and mint leaf extract (40 mg/ $\mathrm{kg}$ b.w.) group 10 males rats for 30 days.

4. T3:Ethidium bromide and silver nanoparticle (40 mg/ $\mathrm{kg}$ b.w.) group 10 males rats for 30 days.

5. T4:Ethidium bromide and (silver nanoparticle, mint leaf extract) group 10 males rats for 30 days.

And after sacrificed males rats we collected tissues samples from testis to extraction of RNA to evaluated of LH,FSH and testosterone by qPCR technique and some tissues to make tissues section to knowledge changes in testis.

The method of induction by ethidium bromide: Gavage of ethidium bromide of experimental group of rats was performed with stomach tube. Etidium bromide was used as in the form of red powder from Merck Company and saline was used as solvent.
Mint leaf extract preparation method: To prepare the mint leaf extract, anumber of fresh mint leaves were prepared. The leaves were washedand their gel was removed. The gel was placed in95 degrees ethanol with four times of their volume.After placing the gel container on the shaker for fourdays, the solution was filtered by a flat filter andconcentrated using the rotary evaporator device at $45^{\circ} \mathrm{C}$. The final material was completely dried at $40^{\circ} \mathrm{C}$ and powdered.Silver nanoparticles were acquired from Nanoshel nanotechnology organization In the US of America.

\section{RESULTS AND DISCUSSION}

The results of the current study, which was conducted on male rats, showed that there is a positive effect of mint leaves extract as well as a negative effect of silver nanoparticles on the level of gene expression for all study groups in each of the LH hormone, FSH hormone and testosterone compared to the control group as shown in the Fig 1,2 and 3. And showed in figure 4, several normal seminiferous tubules with normal spermatogonia cell, normal Sertoli cells, normal germ cell layer with normal maturation stages; interstitial spaces show an area of interstitial congestion; the lumen devoid of spermatozoa with interstitial congestion; normal seminiferous tubules with normal spermatogonia cell, normal Sertoli cells, and normal germ cell layer; maturation arrest of tubules and mild interstitial congestion; seminiferous tubules with atrophy exhibiting thick double cell layers indicative of cessation of spermatogenesis.

Figure 1: Fold change (mRNA transcript level) of FSH gene expression in male rats. No. 10 males per each. Different letters represent significant difference between groups $(\mathrm{p}<0.05)$.

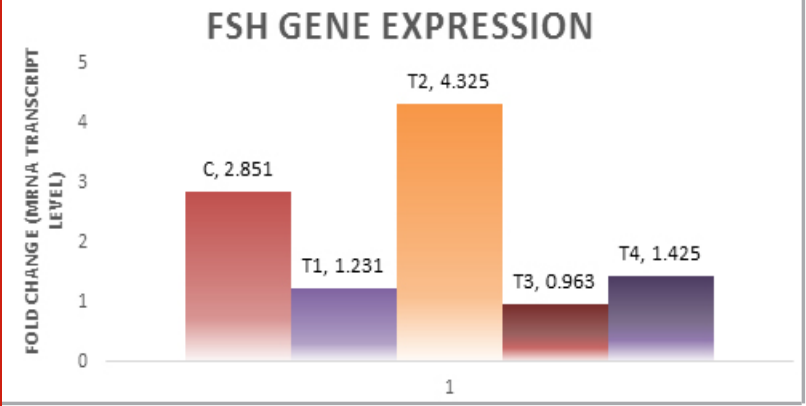

Mint is a herbal plant which is usually recommended for treatment of many diseases, particularly digestive system problems; however, some studies show that despite its beneficial effects, mint has adverse effects on the reproductive system of male rats. Therefore, this study was designed to investigate the effects of mint leaves extract on the male reproductive system and fertility outcome. For successful fertility, normal structure and accurate function of all parts of reproductive system is needed. A complex mechanism under the regulated function of the hypothalamic-pituitary-gonadal axis (HPG axis) is responsible for initiation and maintenance of spermatogenetic activity. Initially, by secretion of 
GnRH (gonadotropin-releasing hormone) from the hypothalamus, FSH and $\mathrm{LH}$ are released from the pituitary gland. In the testes, under the stimulatory action of LH, the Leydig cells, located in interstitial tissue, produce and secrete testosterone.

Figure 2: Fold change (mRNA transcript level) of LH gene expression in male rats.

No. 10 males per each. Different letters represent significant difference between groups $(\mathrm{p}<0.05)$.

\section{LH GENE EXPRESSION}

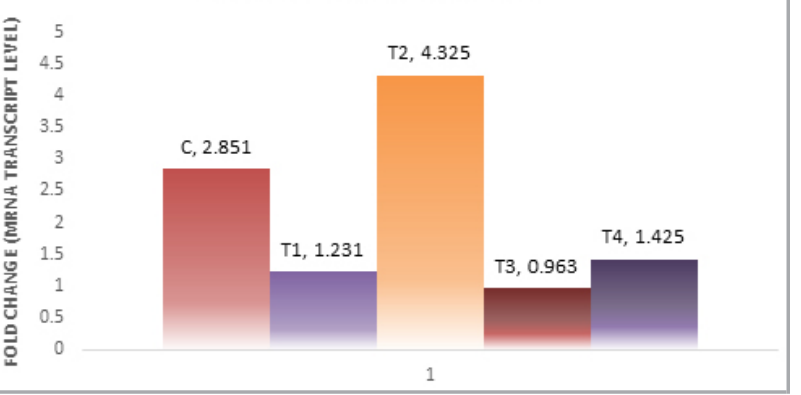

Figure 3: Fold change (mRNA transcript level) of testosterone gene expression in male rats.

No. 10 males per each. Different letters represent significant difference between groups $(\mathrm{p}<0.05)$.

\section{TESTOSTERONE GENE EXPRESSION}

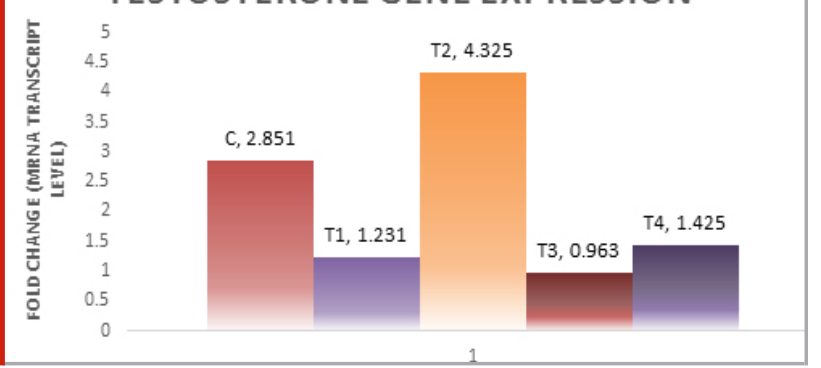

Simultaneously, FSH supports the function of sertoli cells, a mediator for effects of testosterone and FSH on germ cells for successful spermatogenesis in seminiferous tubules. After that, produced sperm pass through the epididymis, which secretes substances for sperm maturation. Ultimately, through the secretion of substances such as fructose, citrate, inositol and prostaglandins from seminal vesicles and secretion of prostatic liquid from the prostate, semen is produced. Thus any pathological changes in male reproductive tissues may interfere with fertility by altering the level of testosterone hormone or disturbing the spermatogenesis and sperm maturation process. In this study, results in normal testosterone level and also sperm concentration and motility, two critical parameters for male fertility (Nieschlag SMA, Nieschlag Behre 2020).

For evaluation of the fertility outcome of male rats, we also determined the number of their offspring born from mating of animals of all 4 groups with untreated females. Since mint administration did not cause any decline in number and motility of sperms, no difference was seen in offspring numbers of experimental male rats compared to control. Moreover, the weight and crown-rump length of offspring were not affected. Therefore, we concluded that treatment of male rats with the mentioned doses of mint extract has no pathological, antiandrogenic or antifertility effects. This result is in contrast with the results of some investigations, which showed that mint has an antiandrogenic effect in male rats (Hafez and Hafez 2005).

Figure 4: Photomicrograph of testes sections after exposure of rats to mint leaves extract and Ag-NPs.

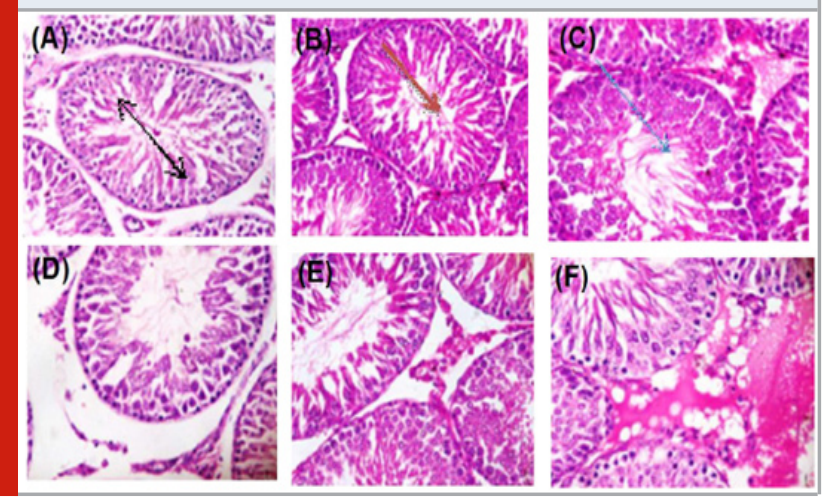

In their studies they used higher doses of mint extract and treated animals in a different way. They steeped mint tea (dried leaves) in a cup of boiling water and added it to the drinking water. So animals received mint continuously at all times for maximum 35 days, while we administered mint in lower doses, once a day for a longer time (45 days). Kumar observed no significant damage to the reproductive system following the short-term use of mint, but long-term use caused irreversible damage to this system, such as significant decrease in the weights of seminal vesicle, epididymis, testis and prostate with significant histopathological changes in these tissues. Also the level of LH and FSH decreased,

which was attributed to generation of oxidative stressin the hypothalamus and pituitary gland, leading to reduced production of GnRH and gonadotropins and resulting in an attenuated level of testosterone and spermatogenesis arrest in treated rats. In addition, severe histopathologic changes were observed in testicular tissue. Similar results were obtained in the study of Akdogan with the same doses and same duration of experiment. But higher levels of LH and FSH were observed in experimental animals followed by decreases in testosterone level and deficiency of spermatogenesis. They explained that an increase in FSH and LH is a normal process which occurs as the result of a decrease in plasma total testosterone levels and concluded that the deficiency of spermatogenesis is the consequence of the direct effect of mint on testicular tissue and Leydig cell dysfunction.

Studies have shown that changes in relative organs and body weight may be a sensitive indicatorof the adverse e ects of drug/chemicals or toxicants (Shittu et al 2015 and Berinyuy;et al 2015). The dose-dependent 
decreases in all sperm velocityparameters, sperm total motility, and progressive motility, and the increases in sperm non-progressivemotility, immobility, and sperm kinematics parameters following treatment with AgNP, compareswell with those of Abu et al. 2013, Madan 2013, where lowtestosterone levels in animals impaired spermatogenesis by causing a decrease in sperm count andmotility, increase in the percentage of defective sperm cells, and altered histomorphology of testisand/ or epididymis.

The significant $(\mathrm{p}<0.05)$ dosed dependent decreases in the hormonal concentrations of LH, FSH, and testosterone in rats dosed Ag-NP for 7 days and 28 days were consistent with previous studieson the effect of different nanoparticles on hormonal levels of male rats. Adebayo et al. 2018 alsoreported a decrease in testosterone, FSH, LH, and prolactin after treatment with CeO2-NP. However,the present study contradicts the findings of Mathias et al. 2015 who reported that Ag-NP administeredto rats at doses of 15 and $30 \mathrm{mg} /$ $\mathrm{kg}$; did not alter the hormonal levels of testosterone, estradiol, FSH, and LH profiles in rats. The low levels of LH and FSH might have hampered the secretion of testosteronefrom the testis with a consequent negative effect on steroidogenesis and spermatogenesis.

The generation of free radicals and induction of oxidative stress are the well-documented cellulareffect of Ag-NP. Ag-NP penetrate the cellular organs particularly the mitochondria which impairsthe membrane potential and induces the production of free radicals, this is evident by the elevatedlevels of $\mathrm{H} 2 \mathrm{O} 2$ and MDA, and the reduction of the activities of antioxidant enzymes, especially catalase,SOD, and GSH observed in testes and epididymis of rats dosed Ag-NP for 7-28 days. The decreasedlevels of catalase, SOD, and GSH after exposure to silver nanoparticles may be due to complexing ofsilver nanoparticles with thiol groups or to the increasing use of GSH, catalase, and SOD todownplay the e_ect of free radicals after exposure to of the nanoparticles.

\section{REFERENCES}

Abu, A., Amuta, P., Buba, E. and Nusa, T., 2013. Evaluation of antispermatogenic effect of Garcinia kola seed extract in Albino rats. Asian Pac J Reprod 2 (1): 15-18.

Adebayo, 0.A., Akinloye, 0. and Adaramoye, 0.A., 2018. Cerium oxide nanoparticle elicits oxidative stress, endocrine imbalance and lowers sperm characteristics in testes of balb/c mice. Andrologia, 50(3), p.e12920. Adenubi, 0.T., Raji, Y., Awe, E.O. and Makinde, J.M., 2010. The effect of the aqueous extract of the leaves of boerhavia diffusa linn. on semen and testicular morphology of male Wistar rats. Science World Journal, 5(2).

Akdogan M, Tamer MN, Cüre E, Cüre MC, Krolu BK, Delibat N. 2007. Effect of spearmint (Mentha spicata Labiatae) teas on androgen levels in women with hirsutism. Phytother Res, 21: 444-447.

Amin G. 2005. Popular medicinal plants of Iran. Tehran University of Medical Sciences Press: Iran.

Berinyuy, E.B., Lawal, B., Olalekan, A.A., Olalekan, I.A., Yusuf, A.A., Sakpe, S. and Ossai, P.C., 2015. Hematological status and organs/body-weight parameters in Wister rats during chronic administration of Cassia occidentalis. International Blood Research \&t Reviews, pp.1-7.

Cakilcioglu U, Khatun S, Turkoglu I, Hayta S. 2011. Ethnopharmacological survey of medicinal plants in Maden (Elazig Turkey). J Ethnopharmacol, 137: 469-486.

Cooper, T.G., 2002. Recent advances in sperm maturation in the human epididymis. Andrologie, 12(1), pp.3851.

Fathi, N.; Hoseinipanah, S.M.; Alizadeh, Z. The e ect of silver nanoparticles on the reproductive system of adult male rats: A morphological, histological and DNA integrity study. Adv. Clin. Exp. Med. 2019, 28, 299-305.

Guimaraes R, Barreira J C, Barros L, Carvalho AM, Ferreira IC. 2011. Effects of Oral Dosage Form and Storage Periodon the Antioxidant Properties of Four Species Used in Traditional Herbal Medicine. Phytother Res, 25: 484-492.

Kumar V, Kural MR, Pereira BMJ, Roy P. 2008. Spearmint induced hypothalamic oxidative stress and testicular anti-androgenicity in male rats - altered levels of gene expression, enzymes and hormones. Food Chem Toxicol, 46: 3563-3570.

Kusemiju, T.O., Osinubi, A.A., Noronha, C.C. and Okanlawon, A.0., 2010. Effect of aqueous extract of the bark of Carica papaya on testicular histology in Sprague-Dawley rats. Nigerian quarterly journal of hospital medicine, 20(3), pp.133-137.

Madan, Z., 2013. Effect of ethanol extract of Carica papaya seeds on the histology of the epididymis of adult male albino mice. Int. J. Sci. Res. Publ, 3, pp.1-5.

Mathias, F.T., Romano, R.M., Kizys, M.M., Kasamatsu, T., Giannocco, G., Chiamolera, M.I., Dias-da-Silva, M.R. and Romano, M.A., 2015. Daily exposure to silver nanoparticles during prepubertal development decreases adult sperm and reproductive parameters. Nanotoxicology, 9(1), pp.64-70.

Naghibi F, Mosaddegh M, Mohammadi Motamed S, Ghorbani A. 2005.Labiatae Family in folk Medicine in Iran. From Ethnobotany to Pharmacology. Iran J Pharm Res, 2: 63-79.

Nieschlag SMA, Nieschlag E, Behre H. 2000. Andrology: Male Reproductive Health and Dysfunction (2nd Edition). Berlin Heidelberg, Spring Springer-Verlag.

Pearson W, Fletcher RS, Kott LS. 2012. Oral rosmarinic 
Acid-enhanced Mentha spicata modulates synovial fluid biomarkers of inflammation in horses challenged with intra-articular LPS. J Vet Pharmacol Ther, 35: 495-502.

Shittu, 0.K., 2018. Diminazene aceturate modified nanocomposite for improved efficacy in acute trypanosome infection.

Shittu, O.K., Lawal, B., Abubakar, N.A., Berinyuy, B.E., Busari, M.B. and Ibrahim, A.0., 2015. Toxicological implications of methanol extract from Nigerian bee propolis on some selected rat tissues. J Pharm Biomed Sci, 5(7), pp.524-31.

Spirling LI and Daniels IR. 2001. Botanical perspectives on health peppermint: more than just an after-dinner mint. J R Soc Health, 121; 62-63.

Talebi, A.R., Khorsandi, L. and Moridian, M., 2013. The effect of zinc oxide nanoparticles on mouse spermatogenesis. Journal of assisted reproduction and genetics, 30(9), pp.1203-1209.

Tayarani-Najaran T, Talasaz-Firoozi E, Nasiri R, Jalali N, MK. 2013. Antiemetic activity of volatile oil from Mentha spicata and Mentha piperita in chemotherapyinduced nausea and vomiting. Ecancermedicalscience, 7: 290 .

Walters, C., Pool, E. and Somerset, V., 2013. Aggregation and dissolution of silver nanoparticles in a laboratory-based freshwater microcosm under simulated environmental conditions. Toxicological \& Environmental Chemistry, 95(10), pp.1690-1701. 